\title{
Model to Estimate Soil Erosion Based on Imaging Analysis
}

\author{
Florin SALA ${ }^{1}$, Mihai HERBEI ${ }^{2 *}$, Cristian CONSTANTINESCU ${ }^{1}$ \\ ${ }^{1}$ Soil Science and Plant Nutrition, Banat University of Agricultural Sciences and Veterinary Medicine \\ "King Michael I of Romania" from Timisoara, Romania \\ ${ }^{2}$ Remote sensing and GIS, Banat University of Agricultural Sciences and Veterinary Medicine "King \\ Michael I of Romania" from Timisoara, Romania \\ *corresponding author: mihai_herbei@yahoo.com
}

BulletinUASVM Horticulture 76(1) / 2019

Print ISSN 1843-5254, Electronic ISSN 1843-5394

DOI:10.15835/buasvmcn-hort: 2018.0022

\begin{abstract}
The study aimed to development a prediction model for soil erosion degree by image analysis techniques. The spectral information was obtained by image analysis in the RGB and HSB color system, and by calculus resulted rgb normalized values. Specific indices were calculated: intensity (INT), normalized difference index (NDI) and dark green color index (DGCI). The correlation analysis emphasized the existence of high levels of interdependence between specific indices and normalized color data rgb, respectively luminance (L). The regression analysis has enabled the creation of estimation models for soil erosion degree (DSE), in the form of linear equations in relation to luminance $\left(R^{2}=0.999, p<<0.001\right.$, RMSEP $\left.=25.5766\right)$ and INT $\left(R^{2}=0.998, p<<0.001\right.$, $\left.R M S E P=25.5833\right)$, and $2^{\text {nd }}$ degree polynomial equations in relation to $\mathrm{DGCI}\left(\mathrm{R}^{2}=0.768, \mathrm{p}<0.001, \mathrm{RMSEP}=28.3275\right)$. Clustering analysis facilitated the grouping of the studied cases in two distinct clusters with four sub-clusters, under conditions of statistical accuracy, Coph. corr. $=0.831$.
\end{abstract}

Key words: DGCI, INT, luminance, NDI, prediction model, soil erosion

\section{Introduction}

A number of limiting factors affect soil and generate environmental imbalances, or limit their productive potential by acidification (Bolan et al., 2005; Zheng, 2010), salinization (Shrivastava and Kumar, 2015; Singh, 2015), desertification (Batterbury and Warren, 2001; Oswald and Harris, 2016), erosion (Uri, 1999, 2001; ), pollution (Saha et al., 2017) etc.

The study and assessment of land and soils affected by limiting factors can be done both by classical methods, as well as by methods based on remote sensing and imaging analysis (Mulder et al., 2011; Shoshany et al., 2013). Classical methods involve going on the field, samplings, measurements, determinations, and therefore having some disadvantages like consuming material, human and time resources. Remote sensing methods have the advantage of providing automated, fast, accurate and repeatable largescale methods for land and soil monitoring and vegetation status indicators, along with detailed data based on environmental sites, which can improve the monitoring and realization of study and prognosis models (Lawley et al., 2016). Methods based on remote sensing and imaging analysis are useful tools for analyzing, characterizing and classifying the territory (Govedarica et al., 2015; Herbei et al., 2015), in precision agriculture (Mulla, 2013; Khanal et al., 2017), in the study of agricultural crop dynamics and estimation of biomass production (Pinter et al., 2003; Herbei and Sala, 2015, 2016; Sun et al., 2017). 
The erosion of land and soils is a limiting factor with varied manifestations in relation to land slope, the vegetation cover, the agricultural crops, the management of the territory and of the vegetation cover or crops, the meteorological phenomena, the anthropic activities of socioeconomic nature, etc. (Boardman et al., 2003; Cerdà and Doerr, 2005; Boardman, 2013; Borrelli et al., 2017; Karidjo et al., 2018; Poesen, 2018). Qualitative depreciation of soil and agricultural land is significant, and the costs for remediation and conservation are also high, but in balance with the environmental and economic benefits of the farms and human communities, they are necessary (Pimentel et al., 1995; Boardman et al., 2009). Numerous studies have approached the erosion process as a result of adverse land damage, and techniques based on satellite, aerial and GIS images have been very useful (Le Bissonnais et al., 2002; Borrelli et al., 2017).
The present study used imaging analysis in order to obtain predictive models of soil erosion degree.

\section{Materials and methods}

The study aimed to assess the state of soil erosion by imaging analysis and the development of prediction models for the erosion degree.

The studied area is located in Bihor County, Budureasa village. The images were taken from the Google Earth system (Fig. 1), with a representation in geographic coordinates. From the base image, different crop images were made with equal dimensions, $305 \times 305$ pixels (Fig. 2), which included the distribution of the erosion degree from maximum to minimum values. The crop images were analyzed with ImageJ (Rasband, 1997) in order to obtain spectral values in the RGB system, correlated with the degree of soil erosion.

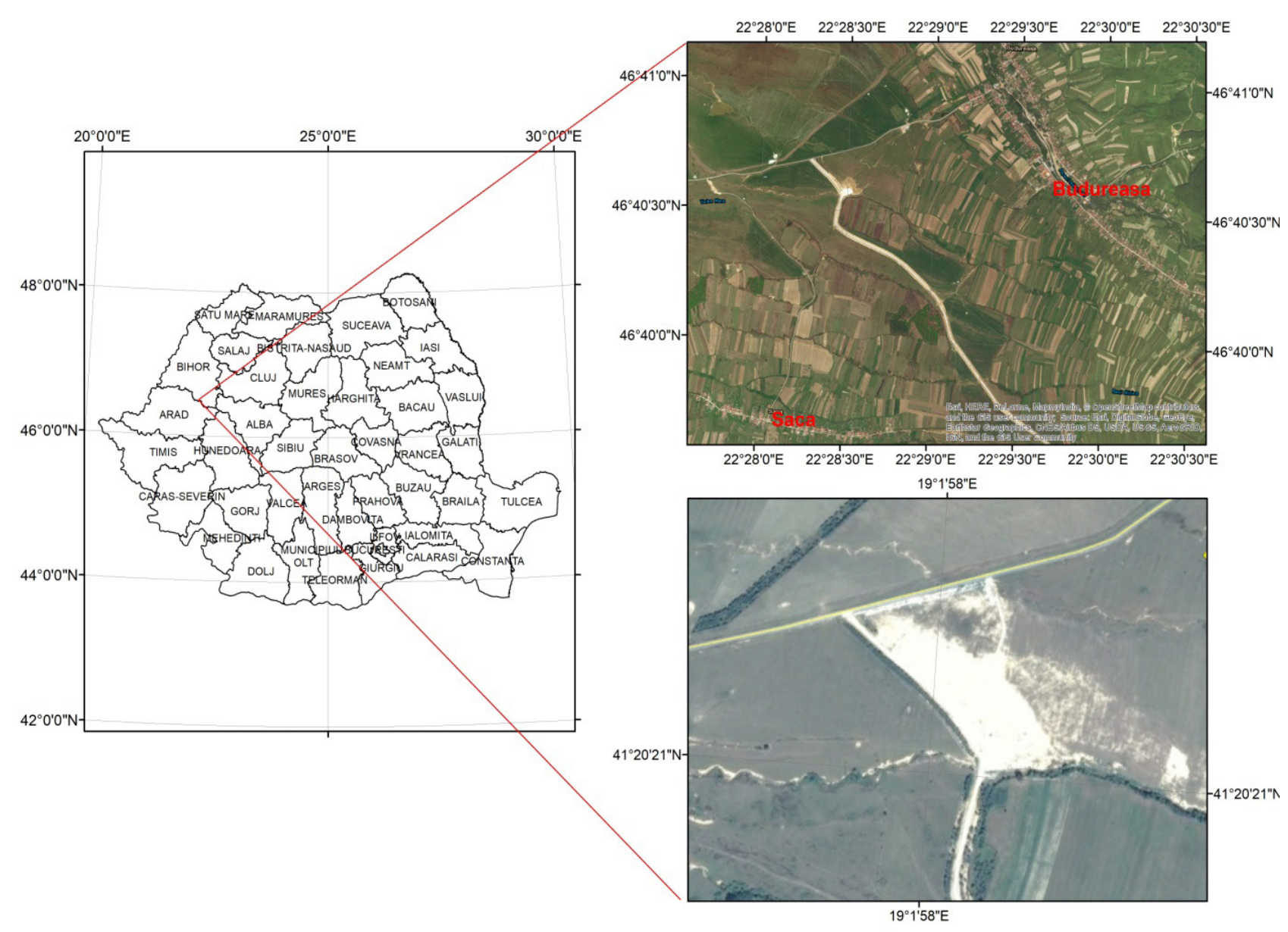

Figure 1. Survey area affected by surface erosion, Bihor County, Saca (Google Earth, 2018 February) 


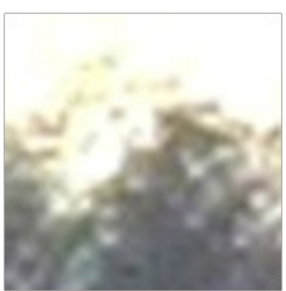

1
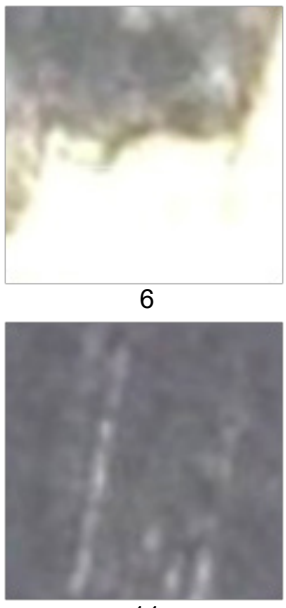

11

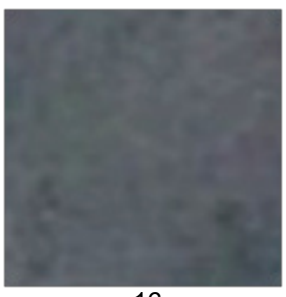

16

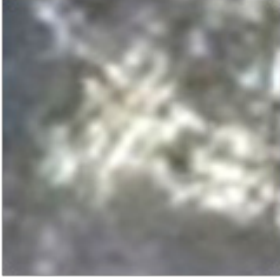

2

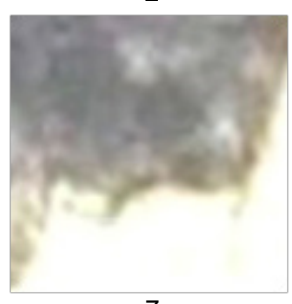

7

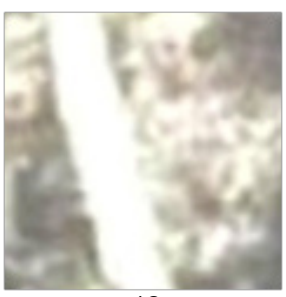

12

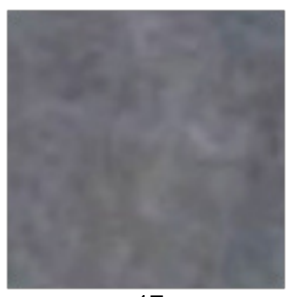

17

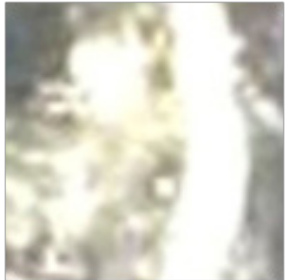

3

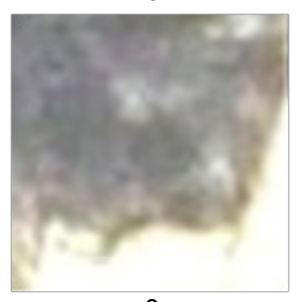

8

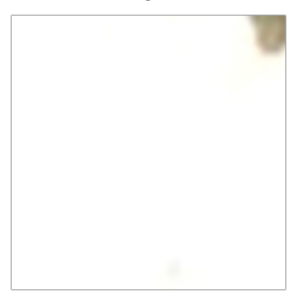

13

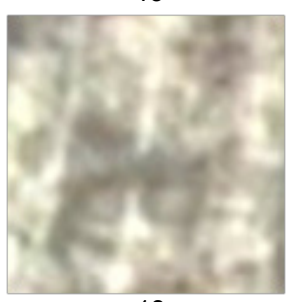

18
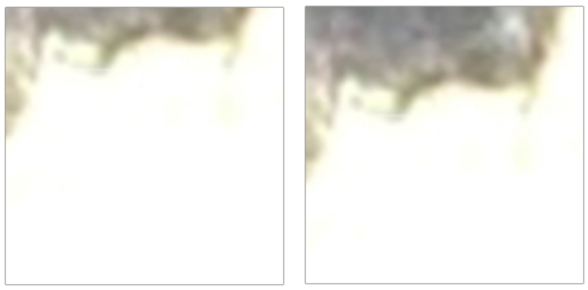

5

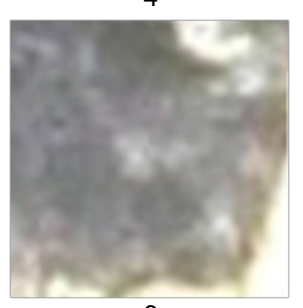

9

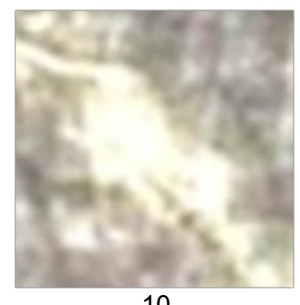

10

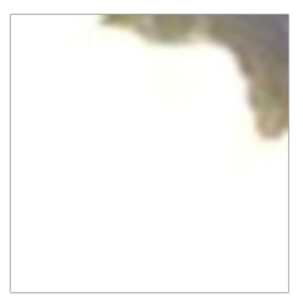

14

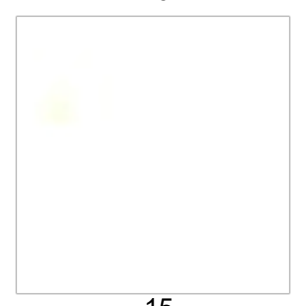

15
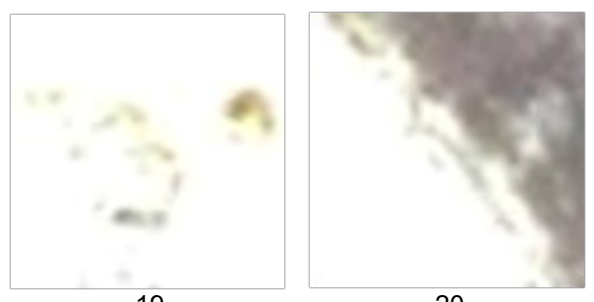

Figure 2. Crop images studied in relation to the distribution of the soil erosion degree

\section{Data in color systems and calculated indices}

The data obtained from the image analysis were expressed in the RGB color system. Based on them, equivalent values were determined in the HSB color system, and the rgb normalized values were calculated, relation (1), (2), (3). Specific indices have been determined for the assessment of the vegetation cover and soil in relation to the degree of erosion, based on the information obtained from the analysis of digital images (Rorie et al., 2011; Lee and Lee, 2013); Intensity - INT (Ahmad and Reid, 1996) relation (4), normalized difference index - NDI (Karcher and Richardson, 2003), relation (5), and Dark Green Color Index - DGCI (Karcher and Richardson, 2003), relation (6).

$$
r=\frac{R}{R+G+B}
$$

$$
g=\frac{G}{R+G+B}
$$

$$
b=\frac{B}{R+G+B}
$$

$$
\begin{aligned}
& \mathrm{INT}=\frac{\mathrm{R}+\mathrm{G}+\mathrm{B}}{3} \\
& \mathrm{NDI}=\frac{\mathrm{r}-\mathrm{g}}{\mathrm{r}+\mathrm{g}+0.01} \\
& \mathrm{DGCI}=\left[\frac{(\mathrm{H}-60)}{60}+(1-\mathrm{S})+(1-\mathrm{B})\right] / 3
\end{aligned}
$$


Degree of Soil Erosion Model - Logical Model

For the approach by imagery analysis of the soil erosion phenomenon, a model was designed including the working phases presented in the logical scheme (Fig. 3).

\section{Statistical analysis of data}

The results obtained were mathematically and statistically analyzed by correlation and regression analysis with the PAST software (Hammer et al., 2001). Linear and polynomial models were obtained for the estimation of soil erosion based on luminance and specific indices, under conditions of statistical accuracy given by $\mathrm{p}$, $\mathrm{R}^{2}$ and RMSEP parameters.

\section{Results and discussions}

From the analysis of the 20 images, that expressed differently the degree of soil erosion, the spectral data in the RGB color system were obtained. Based on them, the equivalent values were determined in the HSB color system, the luminance (L) and the normalized rgb values were

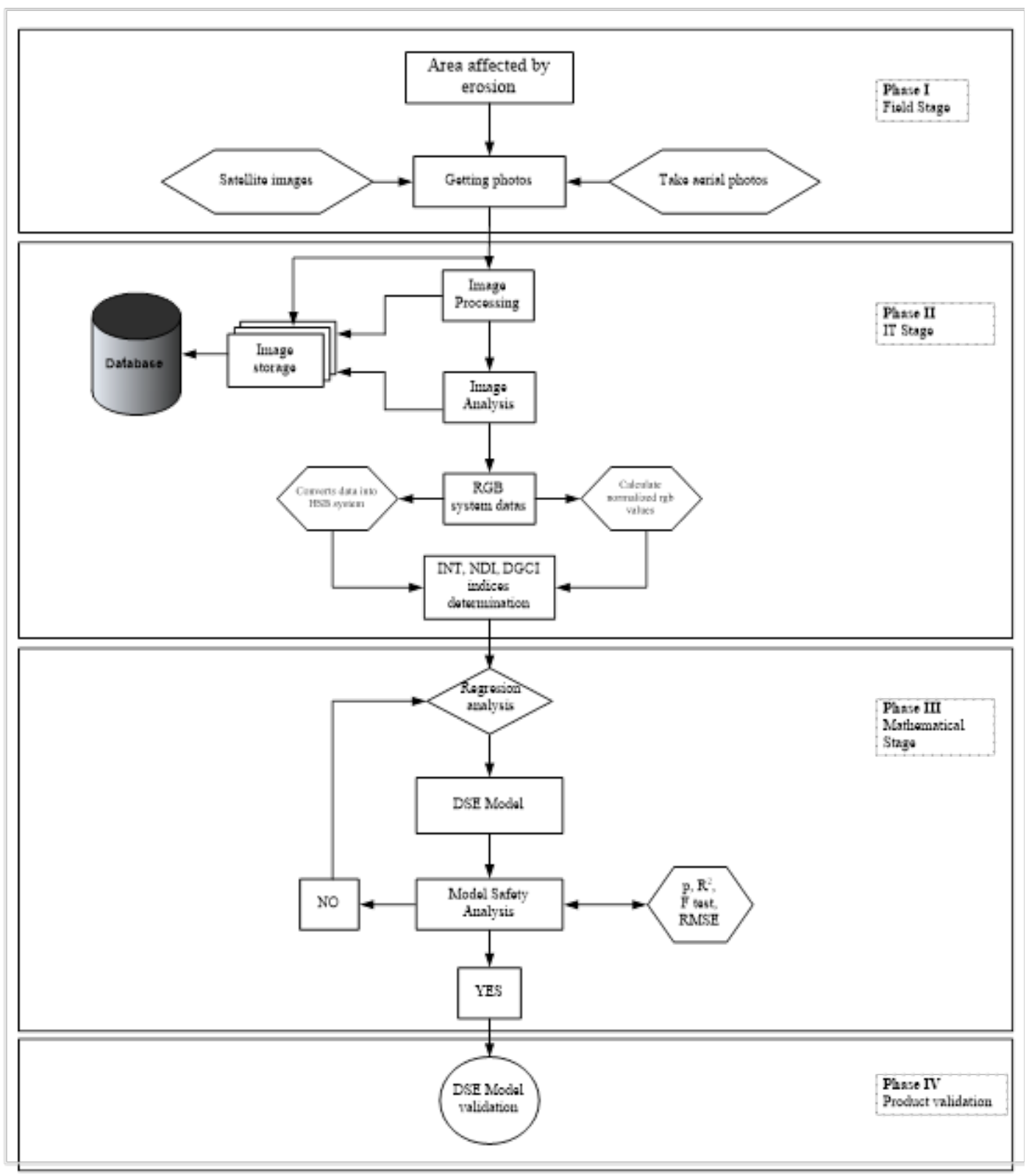

Figure 3. Degree of Soil Erosion Model - Logical schema 
calculated. Consequently, the values of the indices INT, NDI and DGCI were calculated (Tab. 1).

Degree of Soil Erosion (DSE) was estimated in relation to luminance. From the analysis of the luminance oscillation values, the maximum value was found $(\mathrm{L}=100)$ in the case of totally eroded surfaces (Figure. 2.15) and the minimum value $(\mathrm{L}=53)$ in the case of surfaces covered with vegetation (Figure. 2.16). As a result, a luminance variance interval of 47 units was found in correspondence with variation range of the erosion degree between $0-100 \%$, and from this correspondence resulted a variation unit $\left(\mathrm{V}_{u}\right)$ of 0.47 luminance values to $1 \%$ erosion. From this, the soil erosion degree (DSE) was determined in relation to luminance, according to the relation (7).

$$
\operatorname{DSE}=\frac{\mathrm{L}_{\mathbf{s}}-\mathrm{L}_{\mathrm{n}}}{\mathrm{V}_{\mathrm{u}}}
$$

where: DSE - degree of soil erosion; $L_{\text {se }}$ - luminance of eroded soil; $\mathrm{L}_{\mathrm{n}}$ - luminance of normal soil; $\mathrm{V}_{\mathrm{u}}$ - variation unit ( 0.47 for this study)

The Anova single factor test, under conditions of Alpha $=0.001$, revealed the existence of variance in the set of experimental values, in relation with the assessed factor, respectively the degree of soil erosion ( $p<<0.001, F>$ Fcrit). The statistical correlation analysis (Tab. 2), has emphasized the existence of correlations and positive or negative interdependencies, with different levels of intensity between normalized rgb values,

Table 1. Spectral values in the RGB and HSB color system, normalized values and specific indices

\begin{tabular}{|c|c|c|c|c|c|c|c|c|c|c|c|c|c|c|}
\hline No. & $\mathbf{R}$ & G & B & H & S & B & $\mathbf{L}$ & $\mathbf{r}$ & g & b & INT & NDI & DGCI & DSE \\
\hline 1 & 208.08 & 207.57 & 201.15 & 51 & 0.03 & 0.82 & 81 & 0.3374 & 0.3365 & 0.3261 & 205.60 & 0.0012 & 0.3333 & 59.57 \\
\hline 2 & 172.38 & 173.15 & 170.08 & 80 & 0.02 & 0.68 & 68 & 0.3343 & 0.3358 & 0.3299 & 171.87 & -0.0022 & 0.5444 & 31.91 \\
\hline 3 & 222.45 & 221.12 & 212.02 & 49 & 0.05 & 0.87 & 86 & 0.3393 & 0.3373 & 0.3234 & 218.53 & 0.0030 & 0.2989 & 70.21 \\
\hline 4 & 247.09 & 246.4 & 242.74 & 45 & 0.02 & 0.97 & 96 & 0.3356 & 0.3347 & 0.3297 & 245.41 & 0.0014 & 0.2533 & 91.49 \\
\hline 5 & 235.97 & 234.98 & 230.66 & 48 & 0.02 & 0.93 & 92 & 0.3363 & 0.3349 & 0.3288 & 233.87 & 0.0021 & 0.2833 & 82.98 \\
\hline 6 & 220.66 & 219.48 & 214.41 & 43 & 0.03 & 0.87 & 86 & 0.3371 & 0.3353 & 0.3276 & 218.18 & 0.0026 & 0.2722 & 70.21 \\
\hline 7 & 208.1 & 206.58 & 201.63 & 50 & 0.06 & 0.8 & 81 & 0.3377 & 0.3352 & 0.3272 & 205.44 & 0.0036 & 0.3244 & 59.57 \\
\hline 8 & 197.87 & 196.27 & 191.37 & 43 & 0.04 & 0.78 & 77 & 0.3379 & 0.3352 & 0.3268 & 195.17 & 0.0040 & 0.2989 & 51.06 \\
\hline 9 & 184.14 & 182.58 & 178.17 & 50 & 0.03 & 0.72 & 72 & 0.3379 & 0.3351 & 0.3270 & 181.63 & 0.0042 & 0.3611 & 40.43 \\
\hline 10 & 214.51 & 210.16 & 198.1 & 42 & 0.08 & 0.84 & 82 & 0.3444 & 0.3375 & 0.3181 & 207.59 & 0.0101 & 0.2600 & 61.70 \\
\hline 11 & 151.88 & 151.04 & 156.16 & 108 & 0.03 & 0.61 & 60 & 0.3308 & 0.3290 & 0.3402 & 153.03 & 0.0027 & 0.7200 & 14.89 \\
\hline 12 & 218.97 & 216.45 & 208.09 & 44 & 0.05 & 0.86 & 85 & 0.3403 & 0.3364 & 0.3234 & 214.50 & 0.0057 & 0.2744 & 68.09 \\
\hline 13 & 254.04 & 253.88 & 253.29 & 60 & 0.00 & 1.00 & 100 & 0.3337 & 0.3335 & 0.3327 & 253.74 & 0.0003 & 0.3333 & 100.00 \\
\hline 14 & 246 & 245.15 & 242.89 & 40 & 0.01 & 0.96 & 96 & 0.3351 & 0.3340 & 0.3309 & 244.68 & 0.0017 & 0.2322 & 91.49 \\
\hline 15 & 254.98 & 255 & 254.83 & 35 & 0.00 & 1.00 & 100 & 0.3334 & 0.3334 & 0.3332 & 254.94 & $-3.9 \mathrm{E}-05$ & 0.19444 & 100.00 \\
\hline 16 & 131.36 & 135.75 & 140.26 & 153 & 0.06 & 0.55 & 53 & 0.3225 & 0.3332 & 0.3443 & 135.79 & -0.0162 & 0.9800 & 0.00 \\
\hline 17 & 146.87 & 146.88 & 152.37 & 120 & 0.03 & 0.6 & 58 & 0.3292 & 0.3292 & 0.3415 & 148.71 & $-3.4 \mathrm{E}-05$ & 0.79 & 10.64 \\
\hline 18 & 210.98 & 207.2 & 193.37 & 47 & 0.09 & 0.83 & 81 & 0.3450 & 0.3388 & 0.3162 & 203.85 & 0.0089 & 0.2878 & 59.57 \\
\hline 19 & 252.96 & 252.82 & 250.21 & 60 & 0.01 & 0.99 & 99 & 0.3346 & 0.3344 & 0.3310 & 252.00 & 0.0003 & 0.3333 & 97.87 \\
\hline 20 & 223.96 & 221.55 & 218.68 & 36 & 0.02 & 0.88 & 87 & 0.3372 & 0.3336 & 0.3292 & 221.40 & 0.0053 & 0.2333 & 72.34 \\
\hline
\end{tabular}

RGB - values in RGB color system; HSB - values in HSB color system; rgb - normalized values; L - luminance; NDI - normalized difference index; INT - Intensity; DGCI - dark green color index 
luminance, indices INT, NDI, DGCI and degree soil erosion (DSE).

Analyzing the data in Table 2, there was observed a very high positive correlation between INT and luminance $(r=0.999)$, high correlation between NDI and $r$ normalized ( $r=0.893)$, and negative correlation between NDI and $b$ normalized $(r=-0.770)$. The DGCI index had high negative correlations with luminance $(r=-0.854)$ and with INT $(\mathrm{r}=-0.845)$, medium correlations, negative with $r$ normalized $(r=-0,771)$ and positive with $\mathrm{b}$ normalized $(\mathrm{r}=0.752)$, as well as low negative correlations with NDI $(\mathrm{r}=-0.692)$ and with g normalized ( $r=-0.588)$. DSE (Degree of Soil Erosion) had very high correlations, positive with luminance $(r=0.999)$ and with INT $(r=0.998)$, high negative correlations with DGCI $(r=-0.854)$ and low correlations, positive and negative with normalized rgb values and NDI index. The high level of correlations between DSE and luminance, respectively indices INT and DGCI, recommended a regression analysis to find a predictive model of soil erosion degree based on the respective indices or normalized rgb values.

Following the logical scheme of the DSE model (Fig. 3), from the regression analysis resulted DSE estimation models based on calculated indices and luminance, in the form of linear or polynomial $2^{\text {nd }}$ degree equations. High precision models of prediction and statistical accuracy of DSE ware obtained based on luminance (L), INT and DGCI.

In the case of luminance, the prediction model of DSE was described by a linear equation (8), under the conditions of $\mathrm{R}^{2}=0.999, \mathrm{p}<<0.001$, RMSEP $=25.5766$.

Table 2. Matrix correlation table

$$
\text { DSE }=1.0051 \mathrm{x}-0.2276
$$

where: $\mathrm{x}=\mathrm{L}$ (luminance)

In the case of INT index, the prediction model of DSE was described by a linear equation, equation (9), under the conditions of $R^{2}=0.998, p<<0.001$, RMSEP $=25.5833$. The graphical distribution of real and predicted values for DSE based on INT index values is shown in Figure 4.

$$
\text { DSE }=0.3953 \mathrm{x}-0.1521
$$

where: $\mathrm{x}=$ INT (Intensity)

In the case of DGCI index, the prediction model of DSE was described by a $2^{\text {nd }}$ degree polynomial equation, equation (10), under the conditions of $\mathrm{R}^{2}$ $=0.768, \mathrm{p}<0.001, \mathrm{RMSEP}=28.3275$. The graphical distribution of actual and predicted values for DSE based on DGCI index is shown in Figure 5.

$$
\mathrm{DSE}=54.617 \mathrm{x}^{2}-119.01 \mathrm{x}+117.26
$$

where: $\mathrm{x}=\mathrm{DGCI}$ (dark green color index)

The clustering analysis based on Euclidean distances generated a dendrogram (Fig. 6), in which the individual cases studied (1-20) were grouped according to the degree of erosion, under conditions of statistical accuracy, Coph. corr = 0.831 . Two distinct clusters were obtained, with 4 sub-clusters, each containing several clusters of the studied cases.

Soil erosion is a geomorphological and land degradation process, by which soil particles in varying amounts are carried from the soil surface by water and wind, correlated with gravitational

\begin{tabular}{lcccccccc}
\hline & $\mathbf{r}$ & $\mathbf{g}$ & $\mathbf{b}$ & $\mathbf{L}$ & $\mathbf{I N T}$ & $\mathbf{N D I}$ & DGCI & DSE \\
\hline $\mathbf{r}$ & 1.000 & & & & & & & \\
\hline $\mathbf{g}$ & 0.759 & 1.000 & & & & & & \\
\hline $\mathbf{b}$ & -0.975 & -0.886 & 1.000 & & & & & \\
\hline $\mathbf{L}$ & 0.425 & 0.354 & -0.425 & 1.000 & & & & \\
\hline $\mathbf{I N T}$ & 0.406 & 0.336 & -0.405 & 0.999 & 1.000 & & & \\
\hline $\mathbf{N D I}$ & 0.893 & 0.386 & -0.770 & 0.365 & 0.350 & 1.000 & & \\
\hline $\mathbf{D G C I}$ & -0.771 & -0.588 & 0.752 & -0.854 & -0.845 & -0.692 & 1.000 & \\
\hline DSE & 0.425 & 0.354 & -0.425 & 0.999 & 0.998 & 0.365 & -0.854 & 1.000 \\
\hline
\end{tabular}




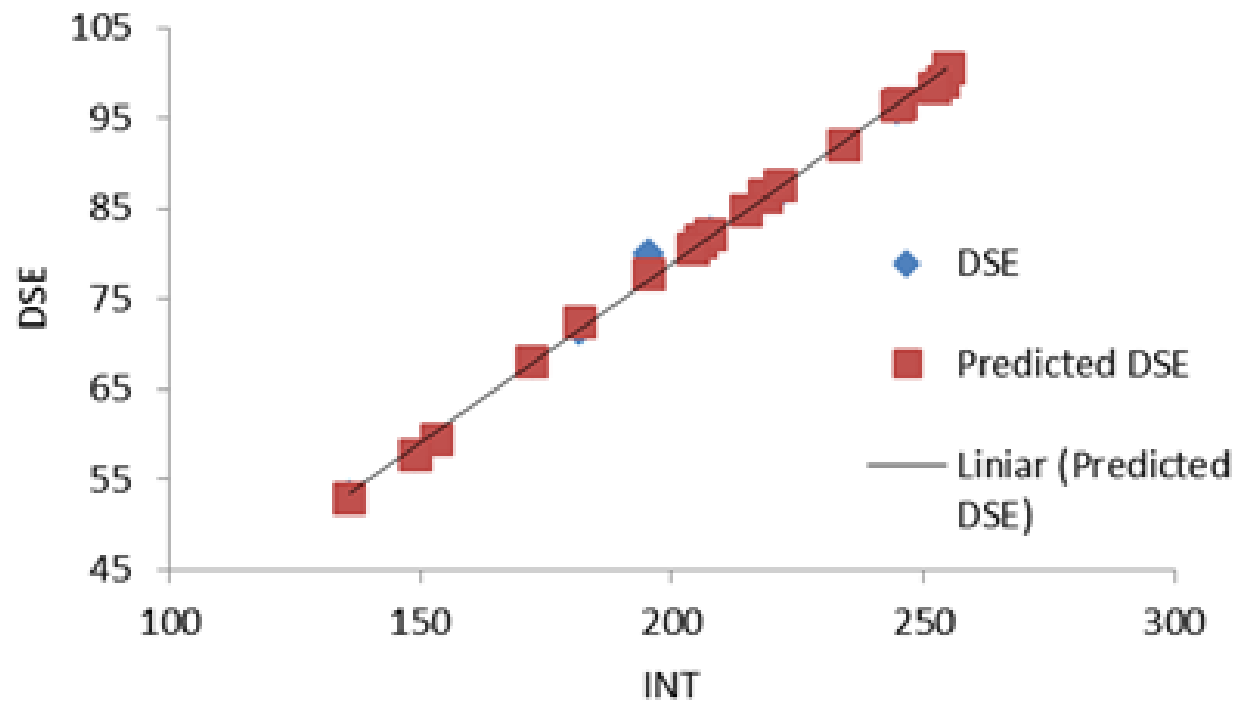

Figure 4. Graphical distribution of actual and predicted DSE values based on INT index luminance

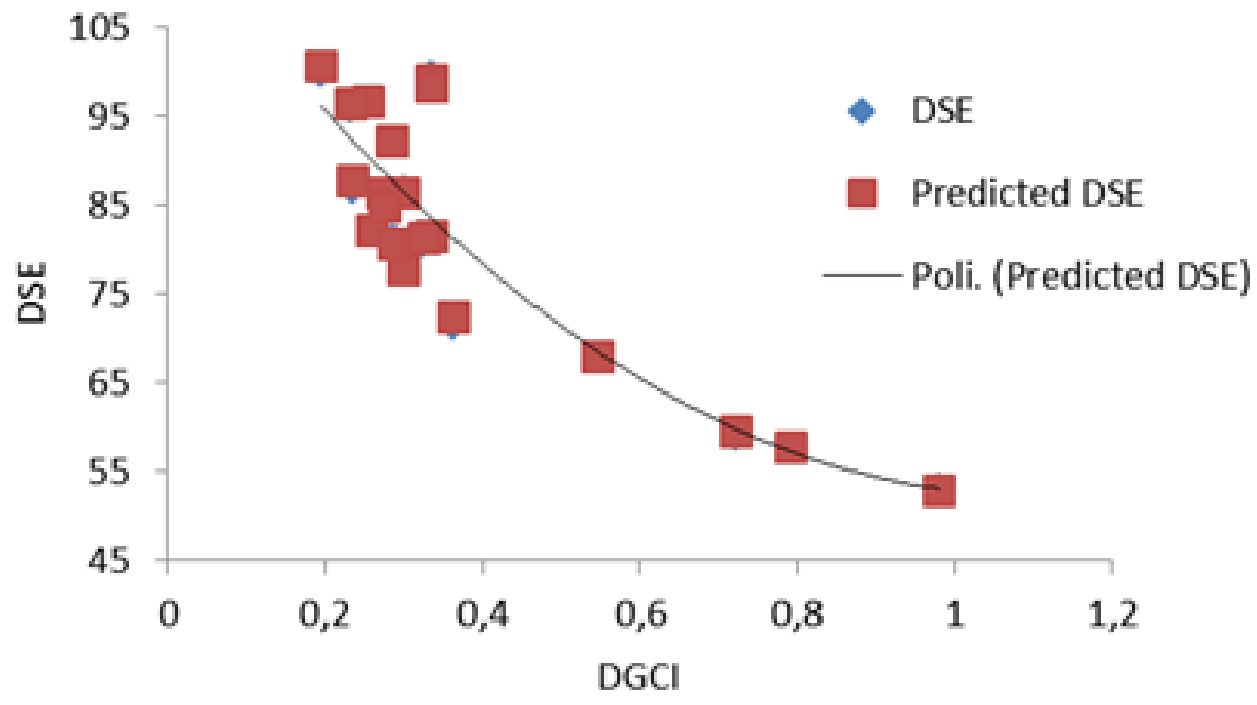

Figure 5. Graphical distribution of actual and predicted DSE values based on the DGCI index

force, and transported and deposited at varied distances from the original site (Evans, 2006; Boardman, 2013). Poesen (2018) believes that more attention is necessary to the study of soil erosion in order to understand the natural, anthropic and interaction factors in the erosion process, to easily and accurately estimate erosion expansion rate in time and space and to develop strategies, accessible and sustainable techniques and methods to reduce the erosion rate. Agricul- tural sites with eroded soils and also those with a risk of erosion are carefully monitored in order to understand the certain phenomenon, to assess the current stage of the amplitude and extension tendency of the erosion, as well as the implementation of conservation methods (Evans, 2013).

Based on soil parameters, vegetation, orographic characteristics of the terrain and correlated with factors of natural (precipitation, wind, slope, 


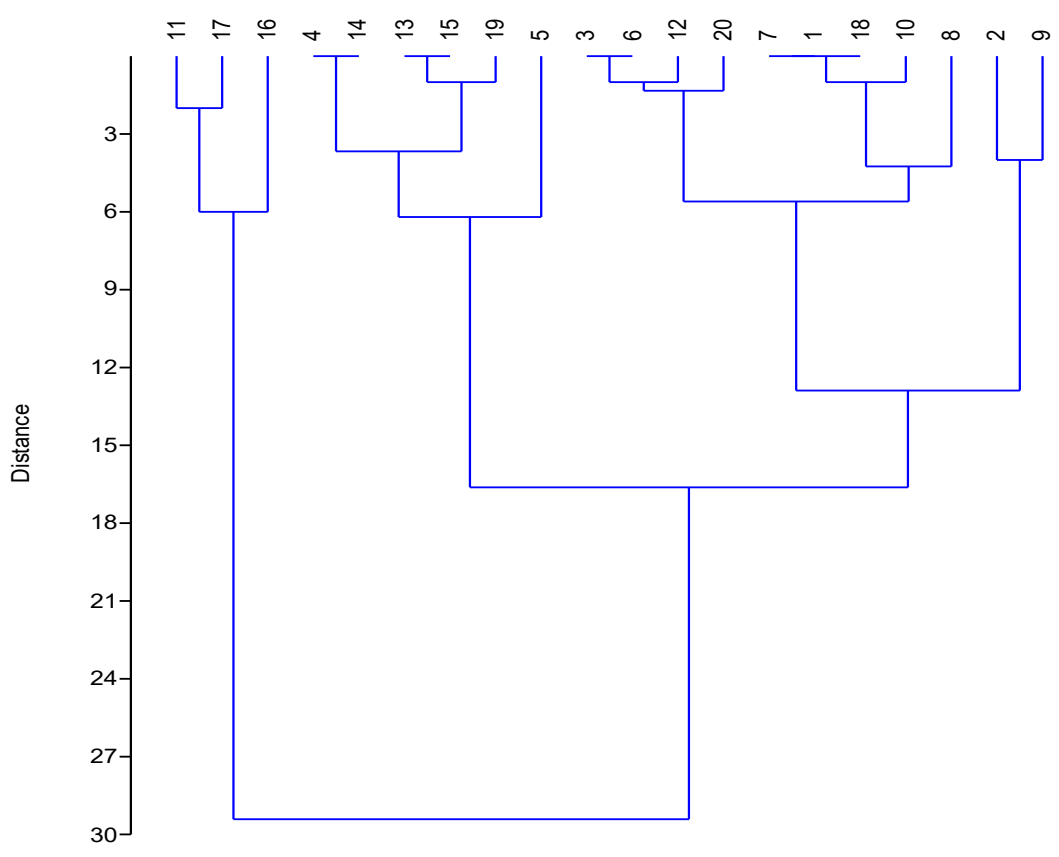

Figure 6. Dendrogram obtained by cluster analysis of the initial data expressing different levels of soil erosion (Numbers 1 to 20 represent crop images studied in relation to the distribution of soil erosion)

etc.) and anthropic influence, different models of soil erosion prediction were developed and used (Evans and Brazier, 2005; Nearing et al., 2006; Wang et al., 2006; Beskow et al., 2009; Ogwo et al., 2012; Gogichaishvili et al., 2014; Silva et al., 2014; Tesfahunegn et al., 2014; Zhang, 2016).

The present study brings to mind an easy method of assessing the degree of soil erosion based on easily accessible images and applications from the public domain. It can be used by local communities for accurate, rapid and cost-free analysis of the erosion process in order to monitor the areas under management.

The model includes the normal situation in the land (image 16) and full land erosion (image 15) as well as a number of intermediate cases. Taking and periodically studying images, especially after periods of torrential rain or snow melt and their analysis, will emphasize immediately changes occurring in the territory, through RGB, rgb, L, NDI, INT and DGCI parameters. The newly obtained values can be entered into the model and immediately show the degree of erosion produced. At the administrative level, intervention decisions can be made to prevent or remedy the identified situations.

\section{Conclusions}

The imaging analysis has proved to be a useful tool for assessing soil erosion, being able to identify the variable erosion levels. The luminance and determinant indices NDI, INT, and DGCI have expressed differently the erosion level and showed correlations of variable levels with DSE.

The regression analysis has enabled obtaining linear and polynomial models of DSE estimation, under conditions of statistical accuracy.

Acknowledgments. The authors thank the Research Center for Environmental Engineering and Geospatial Data from BUASMV "King Michael I of Romania" Timisoara, to facilitate obtaining images and processing them for this study.

\section{References}

1. Ahmad IS, Reid JF (1996). Evaluation of color representations for maize images. J Agr Eng Res, 63(3): 185-195.

2. Batterbury S, Warren A (2001). Desertification. International Enciclopedia of the Social \& Behavioral Sciences, 3526-3529.

3. Beskow S, Mello CR, Norton LD, Curi N, Viola MR, Avanzi JC (2009). Soil erosion prediction in the Grande River Basin, Brazil using distributed modeling. Catena 79(1): 49-59. 
4. Boardman J (2013). Soil Erosion in Britain: Updating the Record. Agriculture. 3: 418-442.

5. Boardman J, Shepheard M, Walker E, Foster IDL (2009). Soil erosion and risk assessment for on- and off-farm impacts: A test case in the Midhurst area, West Sussex, UK J Environ Man, 90(8): 2578-2588.

6. Boardman J, Poesen J, Evans R (2003). Socio-economic factors in soil erosion and conservation. Environ Sci Pol, 6(1): 1-6.

7. Bolan NS, Curtin D, Adriano DC (2005). Acidity. Enciclopedia of Soil in the Environment, 11-17.

8. Borrelli P, Robinson DA, Fleischer LR, Lugato E, Ballabio C, Alewell C, Meusburger K, Modugno S, Schütt B, Ferro V, Bagarello V, Van Oost K, Montanarella L, Panagos P (2017). An assessment of the global impact of 21st century land use change on soil erosion. Nat Commun, 8: 2013.

9. Cerdà A, Doerr SH (2005). Influence of vegetation recovery on soil hydrology and erodibility following fire: an 11-year investigation. Int J Wildland Fire, 14(4): 423438.

10. Evans R (2013). Assessment and monitoring of accelerated water erosion of cultivated land - When will reality be acknowledged? Soil Use Man, 29(1): 105-118.

11. Evans R (2006). Curtailing water erosion of cultivated land: An example from north Norfolk, eastern England. Earth Surf Proc Land, 31(5): 598-605.

12. Evans R and Brazier R (2005). Evaluation of modelled spatially distributed predictions of soil erosion by water versus field-based assessments. Environ Sci Pol, 8(5): 493-501.

13. Gogichaishvili GP, Kirvalidze DR, Gorjomeladze OL (2014) Testing of the hydromechanical prediction model of soil erosion under the conditions of Georgia. Eurasian J Soil Sci, 47(9): 917-922.

14. Govedarica M, Ristic A, Jovanovic D, Herbei MV, Sala F (2015). Object oriented image analysis in remote sensing of forest and vineyard areas. BulletinUASVM Horticulture, 72(2): 362-370.

15. Hammer $\varnothing$, Harper DAT, Ryan PD (2001). PAST: paleontological statistics software package for education and data analysis. Palaeontol Electron, 4(1): 1-9.

16. Herbei MV, Sala F (2015). Use landsat image to evaluate vegetation stage in sunflower crops. AgroLife Sci J, 4(1): 79-86.

17. Herbei M, Sala F, Boldea M (2015). Using mathematical algorithms for classification of Landsat 8 satellite images. AIP Conf. Proc. 1648, 670004-1-670004-4. Doi: https:// doi.org/10.1063/1.4912899

18. Herbei M, Sala F (2016). Biomass prediction model in maize based on satellite images. AIP Conf Proc 1738: 350009-1 350009-4. Doi: https://doi.org/10.1063/1.4952132

19. Karcher DE, Richardson MD (2003). Quantifying turfgrass color using digital image analysis. Crop Sci, 43(3): 943951. Doi: $10.2135 /$ cropsci2003.9430

20. Karidjo BY, Wang Z, Baubacar Y, Wei C (2018). Factors influencing farmers' adoption of soil and water control technology (SWCT) in Keita Valley, a Semi-Arid Area of Niger. Sustainability 10: 288. Doi: 10.3390/su10020288

21. Khanal S, Fulton J, Shearer S (2017). An overview of current and potential applications of thermal remote sensing in precision agriculture. Comput Electron Agric, 139: 22-32. DOi: https://doi.org/10.1016/j.compag.2017.05.001

22. Le Bissonnais Y, Montier C, Jamagne M, Daroussin J, King D (2002). Mapping erosion risk for cultivated soil in France. Catena 46(2-3): 207-220. Doi: https://doi.org/10.1016/ S0341-8162(01)00167-9

23. Lee K-J, Lee B-W (2013). Estimation of rice growth and nitrogen nutrition status using color digital camera image analysis. European Journal of Agronomy 48, 57-65. Doi: https://doi.org/10.1016/j.eja.2013.02.011

24. Lowley V, Lewis M, Clarke K, Ostendorf B (2016). Sitebased and remote sensing methods for monitoring indicators of vegetation condition: An Australian review. Ecol Indic, 60: 1273-1283. Doi: https://doi.org/10.1016/j. ecolind.2015.03.021

25. Mulder VL, de Bruin S, Schaepman ME, Mayr TR (2011). The use of remote sensing in soil and terrain mapping - A review. Geoderma, 162(1-2): 1-19. Doi: 10.1016/j. geoderma.2010.12.018

26. Mulla DJ (2013). Twenty five years of remote sensing in precision agriculture: Key advances and remaining knowledge gaps. Biosyst Eng, 114(4): 358-371. Doi: https://doi.org/10.1016/j.biosystemseng.2012.08.009

27. Nearing M, Renard K, Nichols M (2005). Erosion prediction and modeling. In: M.G. Anderson and J.J. McDonnell (Editors), Encyclopaedia of Hydrological Sciences. John Willey \& Sons Lds., Chichester, pp. 12211228. Doi: https://doi.org/10.1002/0470848944.hsa084

28. Ogwo V, Ogbu KN, Okoye CJ, Okechukwu ME, Mbajiorgu CC (2012). Comparison of soil erosion models for application in the humid tropics. Spec Publ Niger Assoc Hydrol Sci 266-278.

29. Oswald J, Harris S (2016). Desertification. biological and environmental hazards, risks, and disasters, 229-256. Doi: https://doi.org/10.1016/B978-0-12-394847-2.00015-2

30. Pimentel D, Harvey C, Resosudarmo P, Sinclair K, Kurz D, McNair M, Crist S, Shpritz L, Fitton L, Saffouri R, Blair R (1995). Environmental and economic costs of soil erosion and conservation benefits. Science 267(5201): 11171123. Doi: $10.1126 /$ science.267.5201.1117

31. Pinter JrPJ, Hatfield JL, Schepers JS, Barnes EM, Moran MS, Daughtry CST, Upchurch DR (2003). Remote sensing for crop management. Photogramm Eng Remote Sensing, 6: 647-664.

32. Poesen J (2018). Soil erosion in the Anthropocene: Research needs. Earth Surf Proc Land, 43(1): 64-84.

33. Rasband WS (1997). ImageJ. U. S. National Institutes of Health, Bethesda,Maryland, USA, pp. 1997-2014.

34. Rorie RL, Purcell LC, Karcher DE, King AC (2011). The assessment of leaf nitrogen in corn from digital images. Crop Sci, 51(5): 2174-2180.

35. Saha JK, Selladurai R, Coumar MV, Dotaniya ML, Kundu S, Patra AK (2017). Soil pollution - An emerging threat to agriculture (pp 386) 
36. Shoshany M, Goldshleger N, Chudnovsky A (2013). Monitoring of agricultural soil degradation by remotesensing methods: a review. Int J Remote Sens, 34(17): 6152-6181.

37. Shrivastava P, Kumar R (2015). Soil salinity: A serious environmental issue and plant growth promoting bacteria as one of the tools for its alleviation. Saudi J Biol Sci, 22(2): 123-131.

38. Silva RM, Santos CAG, Silva AM (2014). Predicting soil erosion and sediment yield in the Tapacurá Catchment, Brazil. J Urban Environ Eng, 8(1): 75-82.

39. Singh A (2015). Soil salinization and waterlogging: A threat to environment and agricultural sustainability. Ecol Indic 57: 128-130.

40. Sun H, Su Z, Lv J, Li L, Wang Y (2017). Dynamic drought risk assessment using crop model and remote sensing techniques. IOP Conf. Series: Earth and Environmental Science 57: 012012.
41. Tesfahunegn GB, Tamene L, Vlek PLG (2014). Soil erosion prediction using morgan-morgan-finney model in a GIS Environment in Northern Ethiopia Catchment. Appl Environ Soil Sci, 2014: Article ID 468751, 15 pages.

42. Uri ND (2001). The environmental implications of soil erosion in the United States. Environ Monit Assess, 66(3): 293-312.

43. Uri ND (1999). Agriculture and the environment - The problem of soil erosion. J Sustain Agric, 16(4): 71-94.

44. Wang E, Xin C, Williams JR, Xu C (2006). Predicting soil erosion for alternative land uses. J Environ Qual, 35(2): 459-467.

45. Zhang XC(J) (2016). Evaluating water erosion prediction project model using Cesium-137-derived spatial soil redistribution data. Soil Sci Soc Am J, 81(1): 179-188.

46. Zheng SJ (2010.) Crop production on acidic soils: overcoming aluminum toxicity and phosphorus deficiency. Ann Bot, 106(1): 183-184. 